\title{
Preparation and quality evaluation of indigenous gluten-free sweet dumpling (Modak) enriched with Asparagus racemosus
}

Shrutika K. Deo, Snehal D. Pande and Poonam S. Patil

Received : 10.04.2018; Accepted : 13.04.2018

See end of the Paper for authors' affiliation

Correspondence to :

Shrutika K. Deo

MIT College of Food

Technology, Aurangabad

(M.S.) India

Email : shrutikadeo1@gmail.

com
- Abstract : Pregnant women require ensuring that their diet provides sufficient nutrients and energy for the foetus to develop and grow appropriately. Her diet needs to be balanced and nutritious - this involves the right balance of proteins, carbohydrates, and fats, and consuming an ample variety vegetables, and fruits. In present study an attempt was made to prepare an indigenous sweet snack, including modification and formulation of gluten free steamed dumpling (rice based steamed Modak). Modak is enriched with asparagus powder to propose a healthy snack for conceiving and lactating women as it promotes mammary secretion and helps in maintenance of foetal growth. Experimental modak stuffing includes fresh coconut, jaggery, anardana powder, asparagus powder and poppy seeds. For variable samples $\mathrm{S}_{0}, \mathrm{~S}_{1}, \mathrm{~S}_{2}$ and $\mathrm{S}_{3}$ (Asparagus powder at the rate of $0,5,10,15 \%$, respectively) sensory evaluation was carried out and ANOVA was applied to study the variance and to know the consumer preference, at the same time physicochemical, shelf life study and textural properties of resultant samples were analyzed. Based on sensory score it was concluded that $5 \%$ level fortification was accepted by consumer.

- Key words : Gluten free steamed dumpling, Asparagus racemosus, ANOVA, Textural analysis

- How to cite this paper : Deo, Shrutika K., Pande, Snehal D. and Patil, Poonam S. (2018). Preparation and quality evaluation of indigenous gluten-free sweet dumpling (Modak) enriched with Asparagus racemosus. Internat. J. Agric. Engg., 11(Sp. Issue) : 37-40, DOI: 10.15740/HAS/IJAE/11.Sp. Issue/ 37-40. 